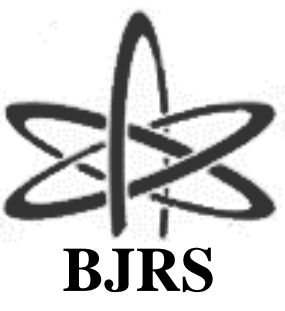
BRAZILIAN JOURNAL $\mathrm{OF}$

\title{
Portable grazing exit X-ray fluorescence system using a low-power X-ray tube
}

\author{
R. S. Santos ${ }^{\mathrm{a}}$, D. F. Oliveira ${ }^{\mathrm{a}}$, J. T. Assis ${ }^{\mathrm{b}}$, M. J. Anjos ${ }^{\mathrm{a}}$ \\ ${ }^{a}$ Instituto de Física / Universidade do Estado do Rio de Janeiro, 20550-013, Rio de Janeiro, RJ, Brasil \\ ${ }^{b}$ Instituto Politécnico / Universidade do Estado do Rio de Janeiro, 28625-570, Nova Friburgo, RJ, Brasil \\ e-mail address of the corresponding author: ramonziosp@yahoo.com.br
}

\begin{abstract}
This work presents the development of a portable grazing exit X-ray fluorescence (GE-XRF) system (geometric $90^{\circ}$ $\left.0^{\circ}\right)$ that can be applied in several areas of science and technology. The portable GE-XRF system employs a mini lowpower (anode of Au) X-ray tube, a SiPIN detector and quartz-disc reflectors as sample support (sample carrier). The grazing exit angle was experimentally determined by measuring with a cooper solution $\left(10 \mu \mathrm{g} . \mathrm{g}^{-1}\right)$. The accuracy of the system was checked using a multielement reference solution as standard reference material. Relative error between measured and reference values ranged from 4 to $19 \%$. Initial results showed that the background was drastically reduced at grazing exit angles, thus enabling trace element analysis. The portable GE-XRF system proved to be stable and reproducible. The present work shows that it is possible to produce a portable, compact, efficient and low-cost grazing exit X-ray fluorescence system with easy-to-handle instrumentation using a low-power X-ray tube and a compact SiPIN detector.
\end{abstract}

Keywords: GE-XRF, Portable system, Trace element analysis.

ISSN: 2319-0612

Accepted: 2018-11-02 


\section{INTRODUCTION}

Total reflection X-ray fluorescence (TXRF) analysis is a well-known surface-sensitive and trace analytical method [1,2]. Grazing exit X-ray fluorescence (GE-XRF) is a new development in X-ray fluorescence analysis related to TXRF [1].

In grazing incidence X-ray fluorescence - the conventional method (GI-XRF) - the primary X-ray beam irradiates the sample at grazing incidence angles and is totally reflected at the sample carrier, with the X-ray fluorescence (XRF) being detected perpendicular to the sample. On the other hand, in GE-XRF the primary X-ray beam irradiates the surface of the sample at an angle of $90^{\circ}$, with the XRF being detected at grazing exit angles. Grazing incidence and grazing exit XRF (GIE-XRF) is a combination of the two methods, wherein the primary beam is directed toward the carrier at grazing incidence and the XRF is detected at grazing exit. Both angles are about zero in this arrangement, while the angle between both beams is $90^{\circ}$ [1].

Grazing exit-XRF can be regarded as an inverted GI-XRF experiment where the X-ray source and detector are exchanged [3]. Becker et al. (1983) demonstrated the equivalence of both techniques from a physical point of view through the principle of microscopic reversibility and reciprocity [4 $6]$.

The technique of GE-XRF has been applied in trace element detection, environmental and biological studies, characterization of thin-film and depth profiling [2, 3, 6-11]. Besides that, the configuration of the GE-XRF allows it to be combined with micro-XRF sources, making micrometric analysis, surface scanning analysis and mapping applications possible. This GE- $\mu$-XRF can be employed using polycapillary X-ray optics [3, 6, 8-10].

This work presents the development of a portable grazing exit X-ray fluorescence (GE-XRF) system using a low-power X-ray tube. The development of this portable GE-XRF system was based on the study of Ashida and Tsuji [2].

\section{MATERIALS AND METHODS}

\subsection{Experimental setup}


The portable GE-XRF system was equipped with a low-power X-ray tube (Mini-X, Amptek Inc.) with a gold anode (maximum voltage $40 \mathrm{kV}$ and current $200 \mu \mathrm{A}$ ) and an XR-100CR SiPIN detector (Amptek Inc.), with a $6 \mathrm{~mm}^{2}$ active area, a $25 \mu \mathrm{m}$ Be window and energy resolution (FWHM) of $145 \mathrm{eV}$ at $5.9 \mathrm{keV}$. The reflectors used as sample support (sample carrier) were $25.4 \mathrm{~mm}$ diameter and $3.0 \mathrm{~mm}$ thick quartz $\left(\mathrm{SiO}_{2}\right)$ discs. This type of reflector has important characteristics for total reflection X-ray, is one of the most widely used in TXRF and has a reflectance of approximately 99.4\%. Figure 1 shows a schematic representation of the GE-XRF experimental setup.

Figure 1: GE-XRF portable system

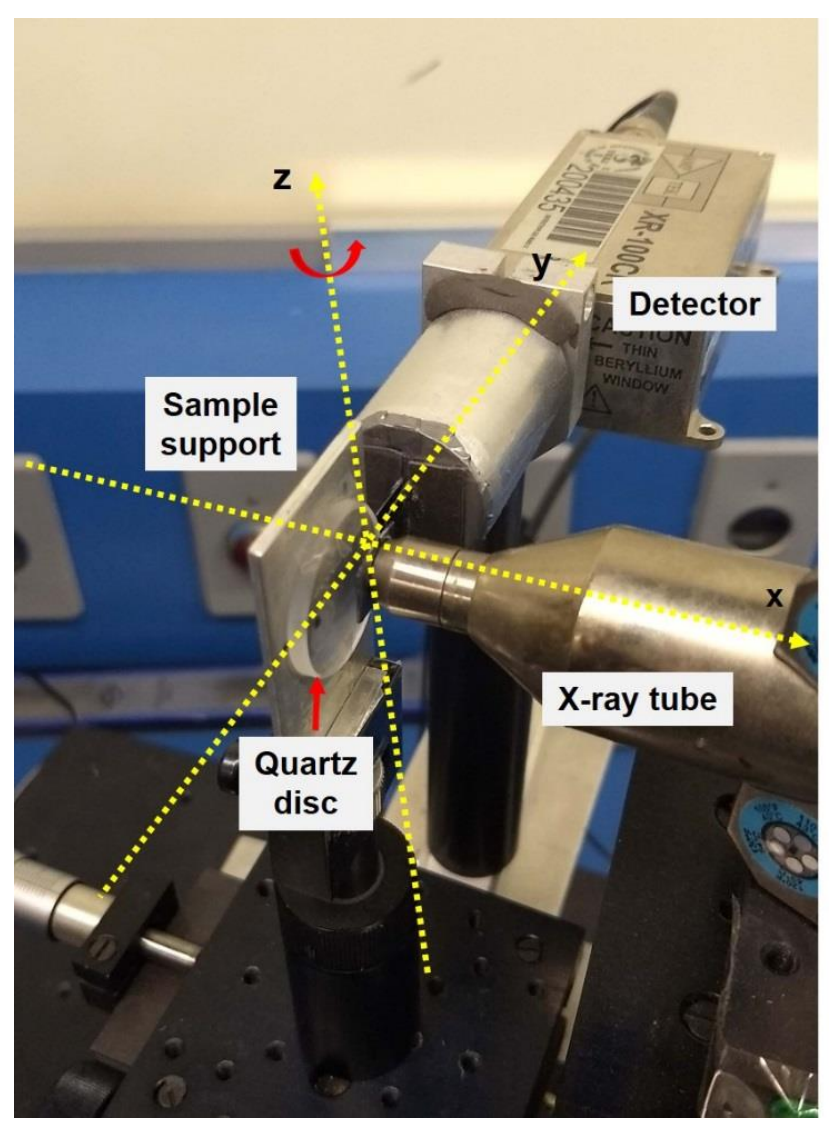

In the portable GE-XRF system, the X-ray tube was placed at $90^{\circ}$ and the detector at about $0^{\circ}$, both angles relative to the sample carrier surface. The sample holder was positioned on top of an X direction-stage (micrometer, minimum resolution: $10 \mu \mathrm{m} / \mathrm{step}$ ) under an angular goniometer (angular 
resolution of 0.03 degrees), making it possible to move relative to the $\mathrm{X}$ direction and perform angular variation (around $\mathrm{Z}$ axes).

The $\mathrm{X}$ direction-stage and the angular goniometer were used to position the sample carrier at the grazing exit angle. Furthermore, the $\mathrm{X}$ direction-stage was used to find the optimal distance from sample carrier to X-ray tube and detector. The optimal distance occurs when the ratio of element intensity to its background (I/B) is maximized. Then, in the same way, an angular scan was performed to find the optimal exit angle, which occurs when I/B is maximized.

A monoelemental sample of cooper $(\mathrm{Cu})$ was used in these tests due to its absorption edge for $\mathrm{K}$ line $(8.90 \mathrm{keV})$ being very close to the excitation energy of the L-lines of the X-ray tube (Au anode, $\mathrm{L} \alpha=9.71 \mathrm{keV}$ and $\mathrm{L} \beta=11.44 \mathrm{keV})$.

\subsection{Sample preparation}

A sample solution with copper (CertiPUR Reference Material, MERCK, stock solution $1000 \mathrm{mg} / \mathrm{L}$ ) was used to characterize the portable system by determining the position and optimal exit angle for this sample. The sample was diluted with Milli-Q water to a final concentration of $10 \mu \mathrm{g} \cdot \mathrm{g}^{-1}$ and a $15 \mu \mathrm{L}$ aliquot was pipetted onto the reflector quartz.

The establishment of the sensitivity curve and the validation of the GE-XRF system were performed using two multielement solutions prepared in-house. The sensitivity curve was obtained using a multielement solution containing the following elements: $\mathrm{P}, \mathrm{S}, \mathrm{Ca}, \mathrm{Sc}, \mathrm{Ti}, \mathrm{V}, \mathrm{Cr}, \mathrm{Fe}, \mathrm{Cu}$ and $\mathrm{Ga}$ (stock solution with concentrations ranging from 10 to $800 \mu \mathrm{g} \cdot \mathrm{g}^{-1}$ ). To validate the analysis methodology of the GE-XRF system, a multielement reference solution containing the elements $\mathrm{S}, \mathrm{Ca}$, $\mathrm{V}, \mathrm{Cr}, \mathrm{Fe}, \mathrm{Cu}$ and $\mathrm{Zn}$ (stock solution with concentration ranging from 15 to $600 \mu \mathrm{g} . \mathrm{g}^{-1}$ ) was used. The element $\mathrm{V}$ was added in both solutions as an internal standard. The solutions were then shaken for homogenization and a $15 \mu \mathrm{L}$ aliquot was pipetted on the reflector quartz. The samples were prepared in triplicate.

\subsection{Analytical Method}


The X-ray tube was operated at a voltage of $20 \mathrm{kV}$ and a current of $100 \mu \mathrm{A}$ in all analyses. Measurement time varied for each analysis, so the measurement time in the positioning and stability tests was $300 \mathrm{~s}$. On the other hand, the measurement time to obtain the sensitivity curve and detection limits was 1000 s. Grazing exit-XRF spectra were processed using the software PyMCA (Python Multichannel Analizer) [12].

Detection limits (LD) were calculated as established by Currie (1968) and later by Tiwari (2005) (Eq. 1) [13, 14]:

$$
D L_{i}=3 \cdot \frac{\sqrt{B g}}{I_{i}} \cdot C_{i}
$$

where $B_{g}$ is the background intensity, $C_{i}$ is the concentration of element $i$ and $I_{i}$ is the intensity of element $i$. All peak intensity and background evaluations were done with the software PyMCA.

\section{RESULTS AND DISCUSSION}

Figures $2 \mathrm{a}$ and $2 \mathrm{~b}$ show the variation of the $\mathrm{X}$-stage and angular scan, respectively, for the intensity of $\mathrm{Cu}$, background and I/B (ratio of $\mathrm{Cu}$ intensity to background intensity).

The optimal position for the $\mathrm{Cu}$ sample was found by analyzing the ratio I/B. In optimal position, the distance from X-ray tube to the sample, and from the sample to the detector, were approximately $17.0 \mathrm{~mm}$ and $35.0 \mathrm{~mm}$, respectively. Figure $2 \mathrm{~b}$ shows the angular scan for the $\mathrm{Cu}$ sample. After finding the optimal distance, an angular scan was performed at this position. The optimal exit angle for this sample was approximately $0.20 \pm 0.05$ degrees. This result is in agreement with the theoretical critical angle for the $\mathrm{Cu}$ K-line energy using a quartz reflector, which is about 0.23 degrees. For the stability and reproducibility tests of the system, thirty sequential measurements and thirty measurements altering the positioning of the sample in each measurement were performed, respectively, using a $\mathrm{Cu}$ sample. The stability and reproducibility tests presented coefficients of variation of $2 \%$ and $4 \%$, respectively, demonstrating that the portable system was stable. 
Figure 2: Characterization of the GE-XRF system. (a) Variation of the X-stage. (b) Variation of the angular scan.

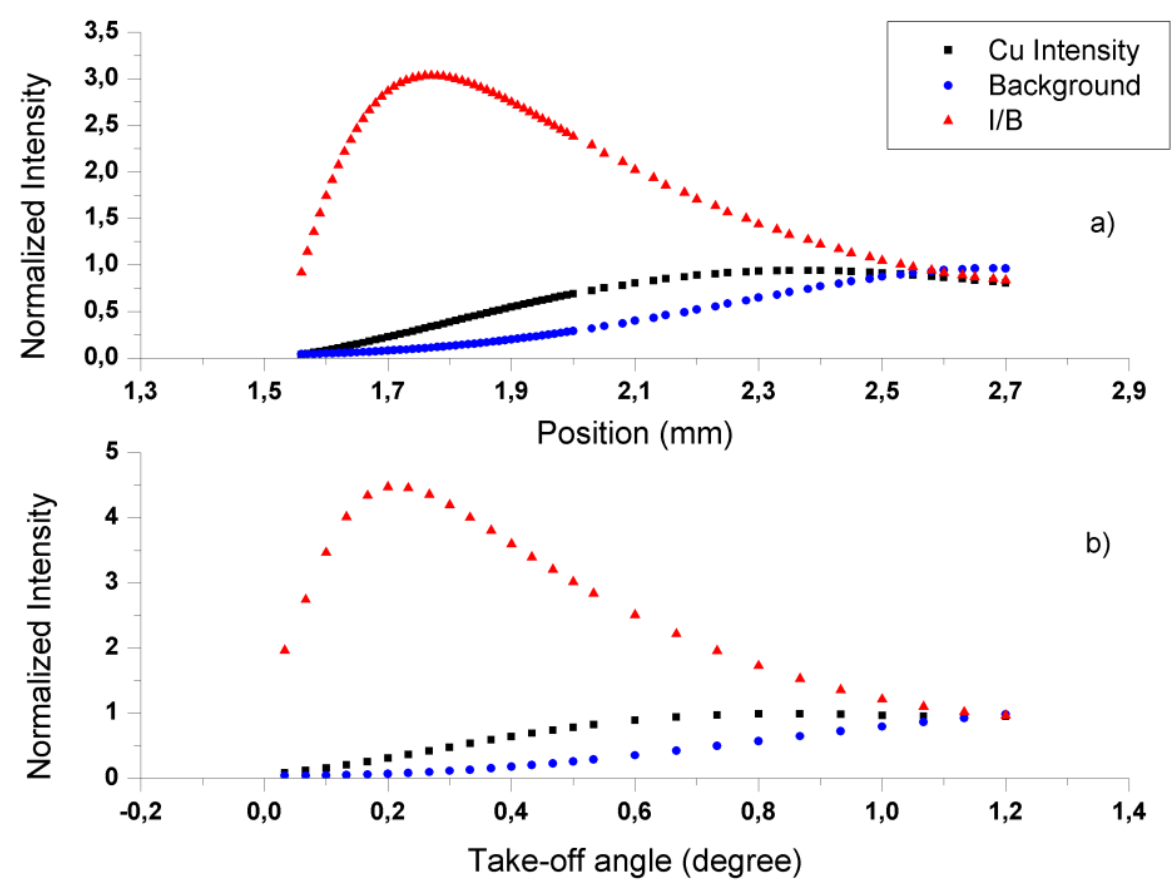

Figures $3 \mathrm{a}$ and $3 \mathrm{~b}$ show the XRF spectra for the $\mathrm{Cu}$ sample. Fig. 3a. shows the XRF spectrum obtained in grazing exit condition. The I/B ratio for $\mathrm{Cu}$ was 28. Peaks of $\mathrm{Ar}$ (the experiment was performed in air) and Au (X-ray tube anode) also appear in the GE-XRF spectrum. Fig. 3b shows the XRF spectrum obtained out of grazing exit condition. In this spectrum the $\mathrm{I} / \mathrm{B}$ ratio for $\mathrm{Cu}$ was 8 , which demonstrates a large contribution by the baseline (background), which occurs because of greater interaction of the emerging beam on the reflector outside the critical angle (large Si peak). 
Figure 3: Typical GE-XRF spectrum for the Cu sample: (a) in grazing exit condition and $(b)$ out of grazing exit condition
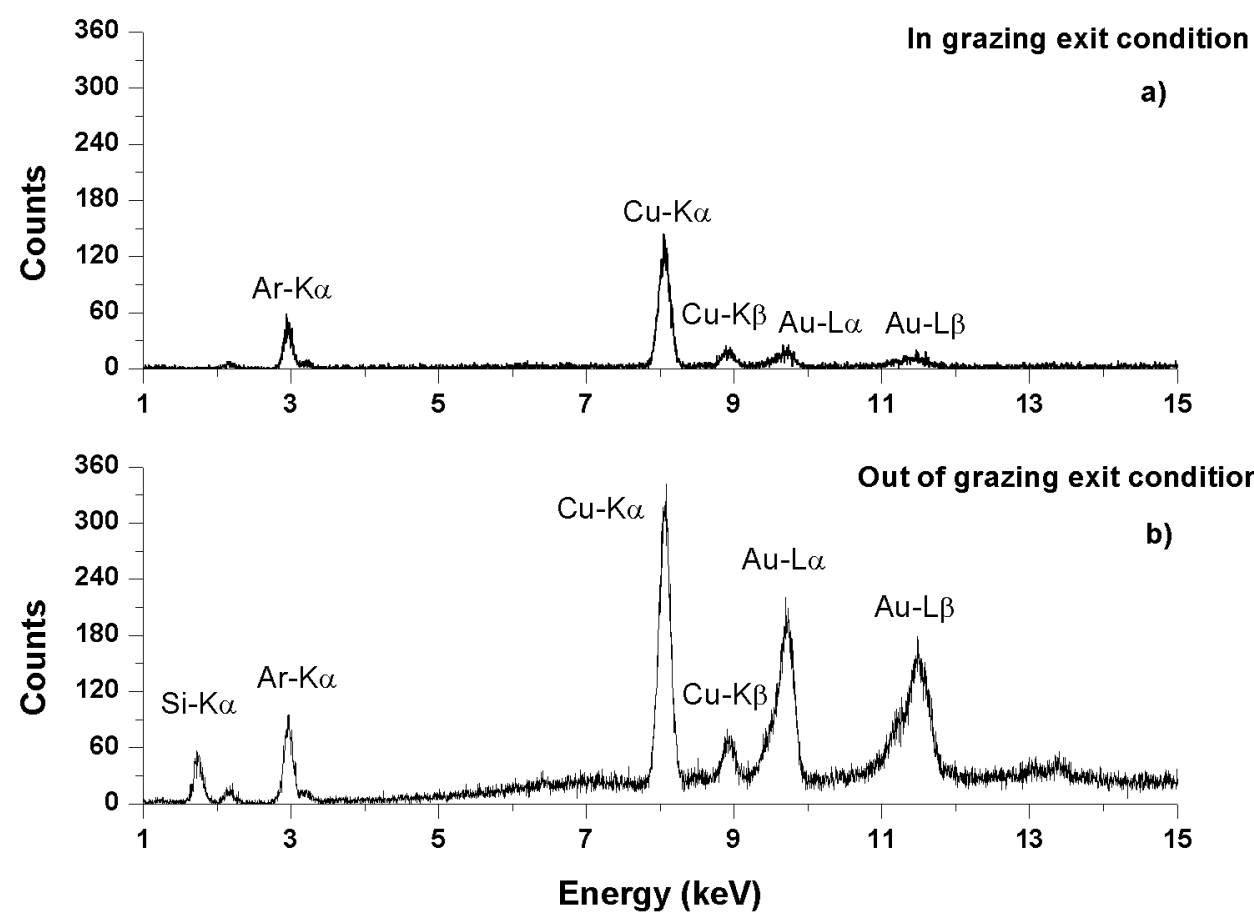

Figure 4 shows the sensitivity curve for the GE-XRF system. The sensitivity curve was calculated using a multielement solution containing 10 elements, and was adjusted to a polynomial curve of the $3^{\text {rd }}$ degree with $\mathrm{R}^{2}=0.99$.

A multielement reference solution was used to obtain the detection limits of the system and to validate the quantitative methodology. Figure 5 shows the spectra obtained for the grazing exit condition of the reference solution. It was possible to detect and quantify all elements of the multielement sample. The elements $\mathrm{Ca}, \mathrm{V}, \mathrm{Cr}, \mathrm{Fe}, \mathrm{Cu}$ and $\mathrm{Zn}$ had concentrations ranging $16-40 \mu \mathrm{g}^{-1} \mathrm{~g}^{-1}$, while $\mathrm{S}$ had a concentration of $600 \mu \mathrm{g} \cdot \mathrm{g}^{-1}$. 
Figure 4: Relative sensitivity curve $\left(S_{R}\right)$ for $K$ lines

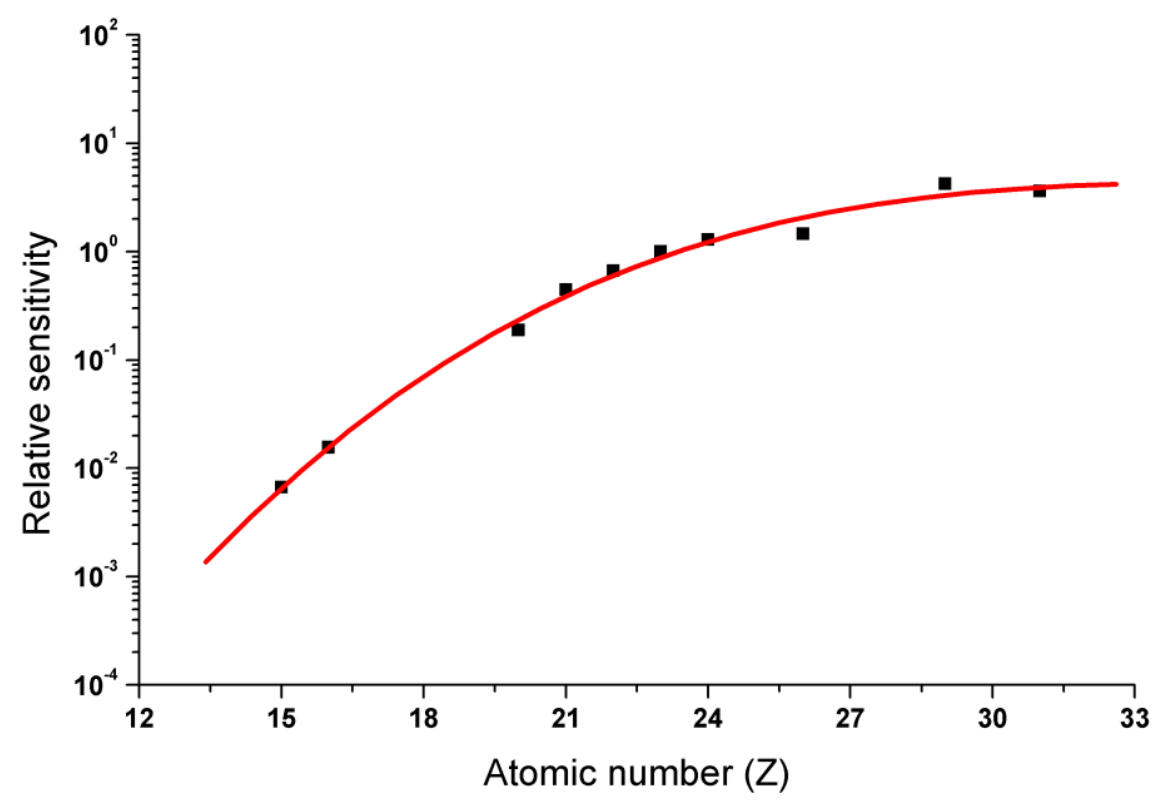

Figure 5: GE-XRF spectrum of the multielement reference sample

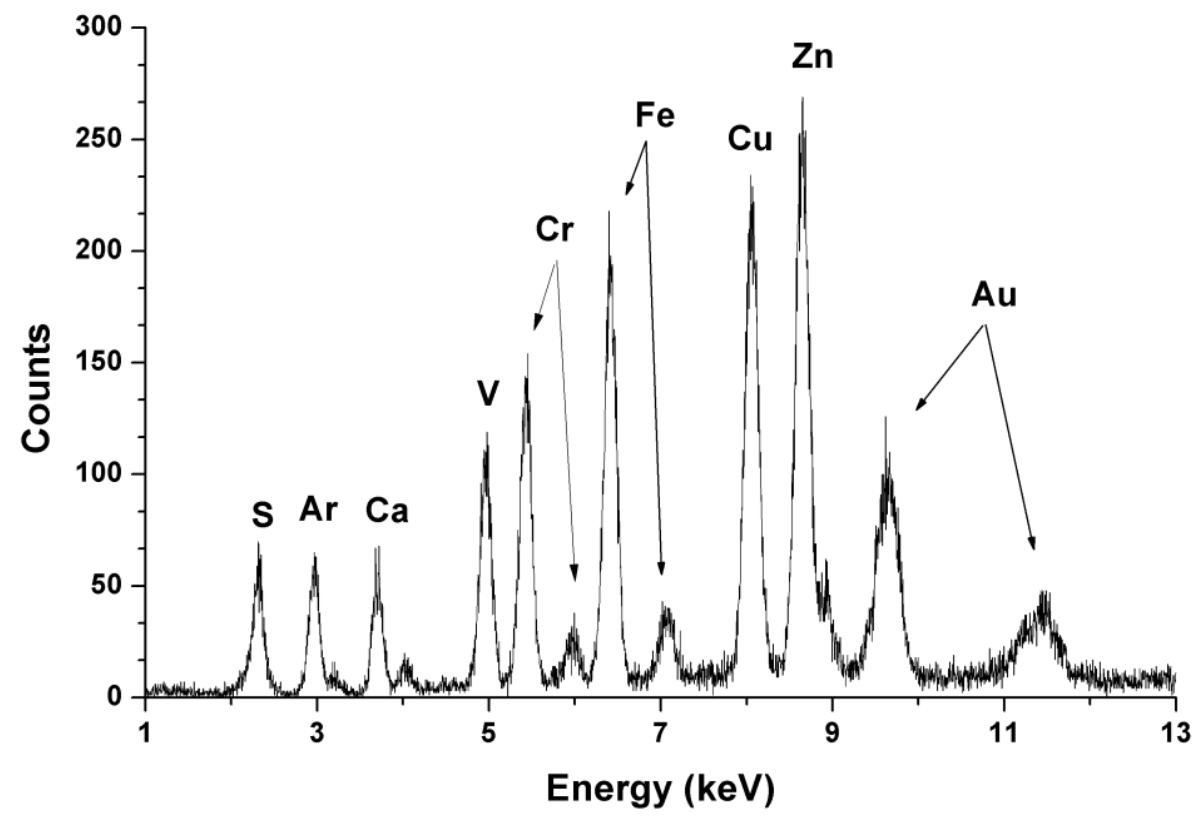


Table 1 shows a comparison between the results obtained with the developed GE-XRF system and the reference values (average \pm standard deviation, coefficient of variation, relative error and detection limit).

Table 1: Results of the multielement reference solution for methodology validation and detection limit

\begin{tabular}{|c|c|c|c|c|c|c|}
\hline \multirow{2}{*}{ Element } & \multirow{2}{*}{$\begin{array}{c}\text { Average }^{\mathrm{a}} \\
\left(\boldsymbol{\mu g . g ^ { - 1 } )}\right.\end{array}$} & \multirow{2}{*}{$\begin{array}{l}\mathbf{C V}^{\mathbf{b}} \\
(\%)\end{array}$} & \multirow{2}{*}{$\begin{array}{c}\text { Reference } \\
\text { value }\left(\mu \mathrm{g} \cdot \mathrm{g}^{-1}\right)\end{array}$} & \multirow{2}{*}{$\begin{array}{c}\text { Relative } \\
\text { Error } \\
(\%) \\
\end{array}$} & \multicolumn{2}{|c|}{$D^{c}\left(\right.$ ng.g $\left.^{-1}\right)$} \\
\hline & & & & & $(\text { This work })^{d}$ & (Ashida \& Tsuji, 2014) \\
\hline $\mathbf{S}$ & $573 \pm 15$ & 3 & $599 \pm 60$ & 4 & $8.2^{\mathrm{e}}$ & - \\
\hline $\mathbf{C a}$ & $39 \pm 1$ & 2 & $40 \pm 4$ & 3 & $0.9^{\mathrm{e}}$ & - \\
\hline $\mathrm{Cr}$ & $18 \pm 2$ & 9 & $20 \pm 2$ & 11 & 235 & 120 \\
\hline Mn & - & - & - & - & 188 & 160 \\
\hline $\mathbf{F e}$ & $19.1 \pm 0.2$ & 1 & $20.3 \pm 2.1$ & 6 & 158 & 121 \\
\hline $\mathbf{C u}$ & $15.0 \pm 0.1$ & 1 & $16.1 \pm 1.6$ & 7 & 126 & - \\
\hline $\mathbf{Z n}$ & $15.9 \pm 0.1$ & 1 & $16.3 \pm 1.6$ & 2 & 129 & 164 \\
\hline Ga & - & - & - & - & 139 & 123 \\
\hline
\end{tabular}

a. Average \pm standard deviation;

b. $\mathrm{CV}=$ coefficient of variation;

c. $\mathrm{DL}=$ detection limit;

d. Extrapolated detection limit;

e. Unit $=\mu \mathrm{g} \cdot \mathrm{g}^{-1}$.

The concentration values found in the multielement sample are in accordance with the reference values. The relative errors between measured and certified values are in the range of 2 to $11 \%$, with an average value of about $6 \%$. It was possible to extrapolate the detection limit (DL) to obtain the detection limits from $\mathrm{S}$ to $\mathrm{Ga}$. The detection limits obtained with the GE-XRF system were in the range of $158 \mathrm{ng} \cdot \mathrm{g}^{-1}$ to $8.2 \mu \mathrm{g} \cdot \mathrm{g}^{-1}$, for Fe and $\mathrm{S}$, respectively. In addition, comparing the DL values obtained by Ashida \& Tsuji with those of the present work (Table 1) revealed that the values for $\mathrm{Mn}, \mathrm{Fe}, \mathrm{Zn}$ and Ga were equivalent. However, the DL obtained in the present study for Cr was approximately $235 \mathrm{ng} \cdot \mathrm{g}^{-1}$, or almost two times higher than the value obtained by Ashida \& Tsuji. This result may be due to the greater distance between the sample and detector in the present work 
(about $35 \mathrm{~mm}$ ) compared to Ashida \& Tsuji (about $10 \mathrm{~mm}$ ). A greater distance between the sample and detector makes the attenuation effects in the air more critical for elements of lower atomic number.

\section{CONCLUSION}

The portable GE-XRF system developed was efficient, showing that it is possible to produce grazing exit X-ray fluorescence using a low-power X-ray tube, a SiPIN detector and a quartz optical disc. Initial results showed that the background was drastically reduced at the grazing exit angle. This feature allows the analysis of trace elements, which makes the system very important in environmental and biological studies. It was also possible to quantify the elements $\mathrm{S}, \mathrm{Ca}, \mathrm{Cr}, \mathrm{Fe}, \mathrm{Cu}$ and Zn with accuracy, having an average relative error of about $6 \%$. Detection limits were compatible with the detection limits found in the literature. Some improvements are being implemented to the system, such as decreasing the sample-detector distance. We believe that this represents the first portable GE-XRF system operating with a low-power tube developed in Brazil.

\section{ACKNOWLEDGMENT}

This work was partially supported by project Qualitec - Bolsas para profissionais nas Unidades de Desenvolvimento Tecnológico (UERJ), Conselho Nacional de Desenvolvimento Científico e Tecnológico (CNPq), Fundação de Amparo à Pesquisa do Estado do Rio de Janeiro (FAPERJ) and Financiadora de Estudos e Projetos (FINEP).

\section{REFERENCES}

[1] Klockenkämper, R.; von Bohlen A. Total-Reflection X-Ray Fluorescence Analysis and Related Methods, $2^{\text {nd }}$ ed. New Jersey \& United States: John Wiley \& Sons, 2015. 
[2] Ashida T.; Tsuji, K. Development of a compact grazing exit X-ray fluorescence spectrometer for fast trace elemental analysis. Spectrochimica Acta Part B, v. 101, pp. 200-203, 2014.

[3] Nowak, S. H.; Banaś, D.; Błchucki, W.; Cao, W.; Dousse, J.-Cl.; Hönicke, P.; Hoszowska, J.; Jabłoński, Ł.; Kayser, Y.; Kubala-Kukuś, A.; Pajek, M.; Reinhardt, F.; Savu, A. V.; Szlachetko, J. Grazing angle X-ray fluorescence from periodic structures on silicon and silica surfaces. Spectrochimica Acta Part B, v. 98, pp. 65-75, 2014.

[4] Becker, R. S.; Golovchenko, J. A.; Patel, J. R. X-ray evanescent-wave absorption and emission. Physical Review Letters, v. 50, pp. 153-156, 1983.

[5] Urbach, H. P.; de Bokx, P. K. Calculation of intensities in grazing-emission X-ray fluorescence, Physical Review B, v. 53, pp. 3752-3763, 1996.

[6] Kayser, Y.; Sá, J.; Szlachetko, J. Depth-Resolved X-ray Absorption Spectroscopy by Means of Grazing Emission X-ray Fluorescence, Analytical Chemistry, v. 87, pp. 10815-10821, 2015.

[7] Tsuji, K.; Takenaka, H.; Wagatsuma, K.; de Bokx, P. K.; Van Grieken, R. E. Enhancement of X-ray fluorescence intensity from an ultra-thin sandwiched layer at grazing-emission angles. Spectrochimica Acta Part B: Atomic Spectroscopy, v. 54, pp. 1881-1888, 1999.

[8] Emoto, T.; Sato, Y.; Konishi, Y.; Ding, X.; Tsuji, K. Development and applications of grazing exit micro X-ray fluorescence instrument using a polycapillary X-ray lens. Spectrochimica Acta Part B, v. 59, pp. 1291- 1294, 2004.

[9] Yang, J.; Tsuji, K.; Lin, X.; Han, D.; Ding, X.; A micro X-ray fluorescence analysis method using polycapillary X-ray optics and grazing exit geometry. Thin Solid Films, v. 517, pp. 3357$3361,2009$. 
[10] Awane, T.; Fukuoka, S.; Nakamachi, K.; Tsuji, K. Grazing Exit Micro X-ray Fluorescence Analysis of a Hazardous Metal Attached to a Plant Leaf Surface Using an X-ray Absorber Method. Analytical Chemistry, v. 81, pp. 3356-3364, 2009.

[11] Kayser, Y.; Szlachetko, J.; Banaś, D.; Cao, W.; Dousse, J.-Cl.; Hoszowska, J.; Kubala-Kukuś, A.; Pajek, M. High-energy-resolution grazing emission X-ray fluorescence applied to the characterization of thin Al films on Si. Spectrochimica Acta Part B, v. 88, pp. 136-149, 2013.

[12] Solé, V. A.; Papillon, E.; Cotte, M.; Walter, Ph.; Susini, J. A multiplatform code for the analysis of energy-dispersive X-ray fluorescence spectra, Spectrochimica Acta Part B, v. 62, pp. 63-68, 2007.

[13] Currie, L. A. Limits for quantitative detection and quantitative determination. Analytical Chemistry, v. 40, pp. 586-593, 1968.

[14] Tiwari, M. K.; Singh, A. K.; Sawhney, K. J. S. Sample Preparation for Evaluation of Detection Limits in X-ray Fluorescence Spectrometry. Analytical Sciences, v. 21, pp. 143-147, 2005. 